\title{
Fundamental Research of Lancing Mechanism in Mitsubishi Continuous Smelting Furnace*
}

\author{
By Etsuji KIMURA ${ }^{* *}$
}

\section{Synopsis}

The injection technique of a jet of gas-solid mixture is used in Mitsubishi Continuous Copper Smelting Process. In order to design the furnace with minimum hearth wear, it is important to know the behavior of a jet of gas-solid mixture into molten bath. But the direct measurement can hardly be made in an industrial plant.

Therefore, the characteristics of a jet of gas-solid mixture were examined in detail using a cold model, and an equation which is able to estimate the penetration depth of solid was derived on the basis of the results obtained. The reliability of this equation was confirmed by laboratory scale hot model experiments.

\section{Introduction}

In Mitsubishi Continuous Copper Smelting Process, raw materials and fluxes are injected with oxygen enriched air into molten bath through vertical lances. ${ }^{1)}$ One of the inherent problems associated with such injection is furnace hearth wear due to errosion $^{2)}$ as has already been experienced in LD steel making process.

The results of fundamental researches on the injection of a jet of gas have been reported in detail. ${ }^{3-5}$ But there is only a few reports on the injection of a jet of gas-solid mixture into liquid. ${ }^{6}$ The purpose of this study is to find out theoretical or experimental model to estimate the penetration depth in molten matte bath where the injection energy of a jet of gassolid mixture extends.

It is difficult to measure directly the penetration depth of a jet of gas-solid mixture into molten matte. Therefore, a cold model was used for the analyses of the behavior of a jet of gas-solid mixture. In order to study this subject, it is necessary to analyse the characteristics of a jet of gas-solid mixture, such as solid velocity, jet cone-angle, and height of nozzle. Further, the penetration depth of solid particles into liquid depends on many other factors, such as feeding rate, density and diameter of solid particle, density and viscosity of liquid, and distribution of particles at a cross-section of jet.

Theoretical and experimental equations were derived to estimate the penetration depth of solid particles under the condition that the density of solid particle is larger than that of liquid. In these equations, the effects of the reaction between solid particle and liquid phase, e.g., dissolution, melting, and evolution of heat and gas, were not considered. The applicability of the equations to a hot model was also checked by studying the characteristics of a jet of gas- solid mixture into a high temperature molten bath. In high temperature experiments, mixtures of copper concentrates, silica and lime were injected into molten matte and the penetration depth was measured. The results obtained were compared with the value calculated from the equation derived on the basis of the results of low-temperature experiments.

A part of this study has already been discussed in the preceding paper ${ }^{2}$ in connection with the hearth wear problem in an actual copper plant.

\section{Applicability of Gas Jet Model to a Jet of Gas-Solid Mixture}

\section{Deformation of Liquid Surface due to Jet}

Deformation of liquid surface owing to a jet of gas has already been studied by Wakelin. ${ }^{3)}$ At the point where a jet of gas impinges on liquid, a cavity is formed. The relationship between the depth of cavity and the condition of impinging gas jet is given by Eq. (1)

$$
\frac{H_{c}}{d_{o}} \cdot\left(\frac{H_{o}+H_{c}}{d_{o}}\right)^{2}=\frac{1}{8} K_{j(g)}^{2} \frac{\rho_{g} U_{o}^{2}}{\rho_{l} g d_{o}}
$$

where, $H_{c}$ : the depth of cavity

$U_{o}$ : the apparent velocity of gas at the outlet of lance

$K_{j(g)}$ : the jet constant of momentum transfer. These factors are shown in Fig. 1.

Takeda and Segawa gave a simplified empirical equation shown below to explain the condition of im-

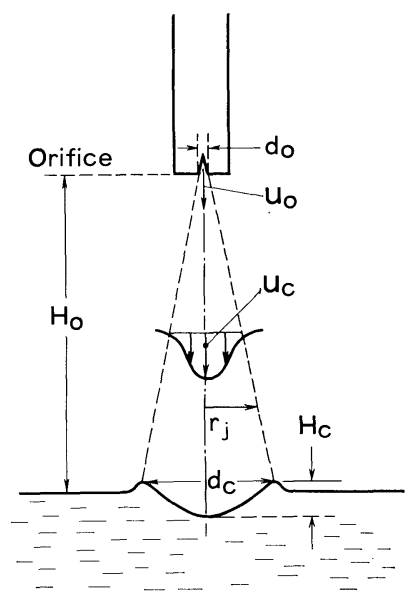

Fig. 1. Model of impinging gas jet.

* Presented to the Symposium of the 140th Committee (Physico-chemical properties of substances at metallurgical temperature), The Japan Soc. for the Promotion of Science (JSPS), on Oct. 31, 1979, at National Research Institute for Metals in Tokyo. Manuscript received September 30, 1982. (C) 1983 ISIJ

** Mitsubishi Metal Research Institute, Kitabukuro-cho, Omiya 330. 
pinging oxygen jet into molten metal bath in a LD converter. ${ }^{5)}$

$$
U_{o} d_{o}=0.73\left(H_{c}+H_{o}\right) \sqrt{H_{c}}
$$

In these equations, the behavior of a jet of gas is correlated to the property of the cavity, but no information is given on the behavior of a jet containing substantial amount of solid particles.

In Mitsubishi Continuous Copper Smelting Furnace, copper concentrates and fluxes are blown through lances together with oxygen enriched air. Theoretical treatment of a jet of gas-solid mixture will be more complicated than the simple case cited above.

From the result of preliminary tests, it was found that cavities of entirely different shapes were formed depending on the condition of jet. The cavity of normal shape (type A) is formed at a relatively low gas flow rate and a low feeding rate of particles. However, when the feeding rate of particles is increased, the mixture of bubbles and solid particles penetrates into liquid more deeply and a cavity of normal shape is not formed (type B).

Three alternative models have therefore been proposed to conform such different conditions:

(1) A jet of gas-solid mixture is approximated by a jet of gas having the density which is equal to the average density of the mixture of gas and solid particles. In this case, Eq. (1) or Eq. (2) can be used for the calculation of the penetration depth of a jet of gas-solid mixture.

(2) All the energy of gas and a part of the impinging energy of solid particles contribute to form a cavity. The depth of cavity will be calculated from an equation derived by modifying Eq. (1). Solid particles impinge at the bottom of cavity and penetrate into liquid until the rest of kinetic energy of particles is consumed.

(3) The cavity of normal shape is not formed clearly at the liquid surface, and impinging solid particles and gas bubbles form the emulsionous dispersion in liquid. Solid particles proceed further downward until the kinetic energy of particles is consumed.

In model 1, Eq. (1) is modified as shown below.

$$
\frac{H_{c}}{d_{o}} \cdot\left(\frac{H_{o}+H_{c}}{d_{o}}\right)^{2}=\frac{1}{8} K_{j(g)}^{2} \frac{\rho_{\theta}^{*} U_{o}^{2}}{\rho_{l} g d_{o}}
$$

where, $\rho_{g}^{*}$ : the average density of gas-solid mixture defined by Eq. (4).

$$
\rho_{g}^{*}=\left(V_{g} \rho_{g}+V_{s} \rho_{s}\right) /\left(V_{g}+V_{s}\right)
$$

In model 2, the depth of cavity $H_{c}$ is calculated from Eq. (5) in which the second term of the right side represents the contribution of solid particles.

$$
\begin{aligned}
\frac{H_{c}}{d_{o}} \cdot\left(\frac{H_{o}+H_{c}}{d_{o}}\right)^{2}= & \frac{1}{8} K_{j(g)}^{2} \frac{\rho_{g} U_{o}^{2}}{\rho_{l} g d_{o}} \\
& +\alpha \frac{1}{8} K_{j(s)}^{2} \frac{\rho_{s g} U_{s}^{2}}{\rho_{l} g d_{o}}
\end{aligned}
$$

where, $\rho_{s g}$ : the weight of particles divided by unit volume of gas

$\alpha$ : the contribution ratio of particles to the penetration depth.

Further, the particles collided to the liquid surface at the bottom of cavity will penetrate to the depth, whereat the velocity of particle is the same as the terminal velocity or is equal to zero. The change in the velocity of particle in liquid is expressed by Eq. (6).

$$
\frac{d U_{s}}{d t}=\left(\rho_{s}-\rho_{l}\right) g / \rho_{s}-C_{d}\left(\frac{3}{4} \rho_{l} U_{s}^{2}\right) / d_{p} \rho_{s}
$$

where, $C_{d}$ : the drag coefficient.

The penetration depth of particle from the collision point is given by integrating Eq. (6) twice with respect to time $t$. Then the total penetration depth of particles is the sum of $H_{c}$ and the penetration depth calculated as above.

In model 3, the penetration depth of particles could be calculated from the density of the mixture of gas and liquid instead of $\rho_{l}$ shown in Eq. (6). But it is very difficult to determine the density of the mixture, because the volume of gas containing particles is influenced by velocity, size distribution and shape and weight of particles, and the volume of gas decreases with the penetration depth in liquid. The penetration depth of particles was correlated experimentally to the above factors, because it is very difficult to determine the penetration depth theoretically in model 3. Experimental results obtained were treated by multivariate regression analysis. Further the propriety of the result was checked by high temperature experiments.

\section{Apparatus and Experimental Methods}

The apparatus used for low-temperature tests is schematically shown in Fig. 2. Solid particles is

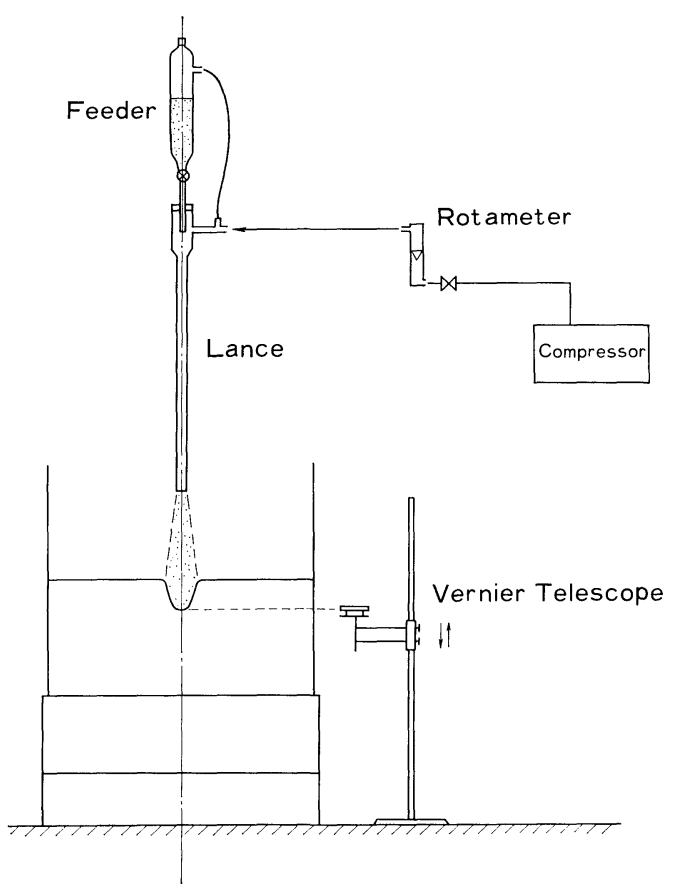

Fig. 2. Apparatus used for impinging gas-solid jet. 
stored in a hopper of $10 l$ capacity. Solid particles in the hopper were fed into a feeder through a rotary valve at definit feeding rate. It was then fed into the air line through a controlled ball-valve. Flow rate of air was $7 \sim 80 \mathrm{Nm}^{3} / \mathrm{hr}$. The feeding rate of particles was $1.1 \sim 14.4 \mathrm{~kg} / \mathrm{hr}$.

Lance: The lance used was straight bore stainless steel nozzle of $12.5 \mathrm{~mm}$ inner diameter and $0.86 \mathrm{~m}$ long.

Tank: The inner dimensions of tank made by vinyl chloride plates of $5 \mathrm{~mm}$ thick were $1.0 \times 1.0 \times 1.0 \mathrm{~m}$.

Particle: Solid particles used were coke, ilmenite ore, glass beads, silica and pyrite.

Liquid: Liquids used for bath were water, carbon tetrachloride and carbon tetrabromide, all of which were transparent so as to allow direct observation.

Measurement of penetration depth: The penetration depth of particles was measured by a Vernier Telescope as shown in Fig. 2. A stress-strain gage was used to measure the impact strength of injection particles in liquid bath and to monitor the decrease in particle velocity at the different depth in liquid bath.

\section{Results of Preliminary Experiments and Se- lection of Applicable Model}

\section{Validity of Eq. (3) for Model 1}

The experimental results obtained are shown in Table 1, compared with the calculated values. It is clear that there is no agreement between these two.

\section{Validity of Eq.(5) for Model 2}

The test was made at a constant gas velocity and various feeding rates in a glass beads-water system. The contribution of solid particles to the formation of cavity was evaluated by measuring the penetration depth. As the value of the first term in the right side of Eq. (5) is constant under these conditions, the plot of

$$
\frac{H_{c}}{d_{o}} \cdot\left(\frac{H_{o}+H_{c}}{d_{o}}\right)^{2}
$$

against $\left(\rho_{s g} U_{s}^{2} / \rho_{l} g d_{o}\right)$ should give a straight line if $\alpha$ is constant. A linear relationship exists as shown in

Table 1. Experimental data and calculated results.

\begin{tabular}{|c|c|c|c|c|}
\hline \multirow[b]{2}{*}{ Liquid } & \multirow{2}{*}{$\begin{array}{l}\text { Solid particles } \\
\quad\left(d_{p}, \mathrm{~mm}\right)\end{array}$} & \multirow{2}{*}{$\underset{(\mathrm{m} / \mathrm{s})}{U_{s}}$} & \multicolumn{2}{|c|}{$\begin{array}{c}\text { Depth of cavity } \\
(\mathrm{cm})\end{array}$} \\
\hline & & & $\begin{array}{l}\text { Calcu- } \\
\text { lated } \\
\text { (Eq. (1)) }\end{array}$ & $\begin{array}{l}\text { Mea- } \\
\text { sured }\end{array}$ \\
\hline $\mathrm{C}_{2} \mathrm{H}_{2} \mathrm{Br}_{4}$ & Glass bease $(0.1)$ & 60 & 8.3 & 35.5 \\
\hline 川 &,$\quad(1.0)$ & 172 & 14.7 & 28.5 \\
\hline " & $川 \quad(1.0)$ & 60 & 12.0 & 40.5 \\
\hline Water & Polyethylene (3.0) & 55.8 & 12.4 & 24.0 \\
\hline $\mathrm{CCl}_{4}$ & " & $"$ & 8.2 & 19.0 \\
\hline$"$ & ” & " & 7.3 & 16.0 \\
\hline $\mathrm{C}_{2} \mathrm{H}_{2} \mathrm{Br}_{4}$ & ” & " & 6.1 & 14.5 \\
\hline " & ” & ” & 5.0 & 13.0 \\
\hline
\end{tabular}

Fig. 3 and the slope of the straight line obtained was the value of $\left(\alpha K_{j(s)}^{2} / 8\right)$, where $K_{j(s)}$ is equal to $4 / \tan \theta$ and $\theta$ is the cone-angle of a jet of solid particles, the measurement of which will be discussed later. In this case, the value of $\alpha$ was 0.09 . On the other hand, the penetration depth of particles in liquid was given by Eq. (6). But in a practical purpose, the penetration depth of particle was negligibly small as compared with the depth of cavity, particulary in case that the density of liquid was larger than that of particles. From these results, the depth of cavity could satisfactorily be estimated from Eq. (5) in case of type A cavity.

\section{Transition Condition between Type $A$ and Type $B$}

There are two different types of cavity depending on the lancing conditions, i.e., type $\mathrm{A}$ and type $\mathrm{B}$ as previously mentioned. Models 1 and 2 can only be applied to type A. The second step of the study is to bend out either of the two, type A and type B, represents the actual lancing mechanism. The characteristic feature of the type B cavity is the formation of gas-liquid emulsion at the lancing area. Therefore, the average density of emulsion phase is much smaller than that of pure liquid, which may allow to penetrate a jet of gas-solid mixture into liquid bath more deepy. To explain the role of solid particles, a simplified model was proposed as shown in Fig. 4.

In Fig. 4, (a) represents an isolated particle that collides on the surface and penetrates into liquid leaving a vacant channel will be filled up quickly as shown in (b). If the feeding rate is large enough, the second particle follows the first one and collids to the surface of liquid before the vacant channel formed by the first one disappears. See Figs. 4. (c) and (d).

In such a condition, fine bubbles may be formed and the life of bubble will become longer and may give temporary gas solid emulsion.

To find the lancing condition under which the transition of phenomena from Figs. 4 (a)-(b) to (c)(d) occurs, a parameter $\mathcal{N}_{j}$ was defined so as to be proportional to the sum of the projected area of parti-

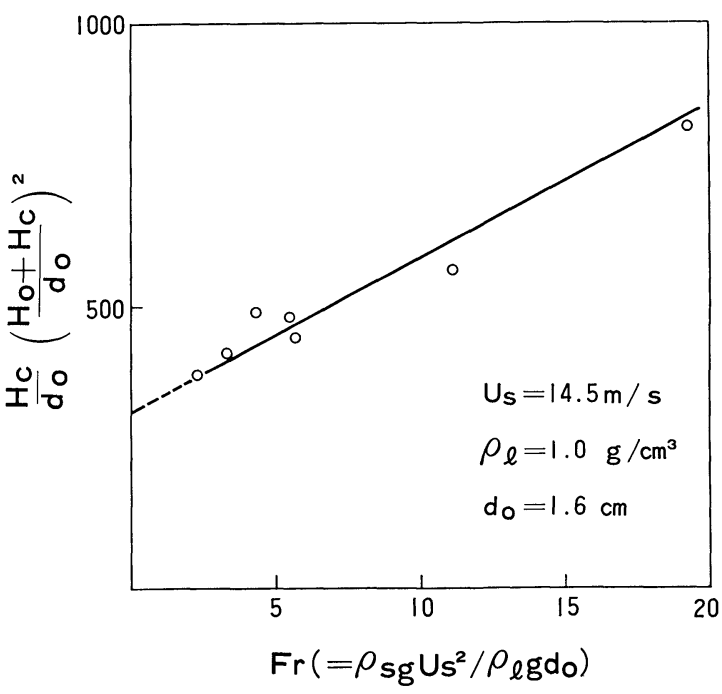

Fig. 3. $\left(H_{c} / d_{o}\right)\left(\left(H_{o}+H_{c}\right) / d_{o}\right)^{2} v s$. $\left(\rho_{s g} U_{s}^{2} / \rho_{l} g d_{o}\right)$. 


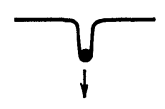

(a)

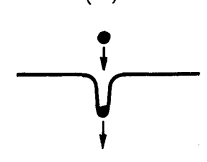

(c)

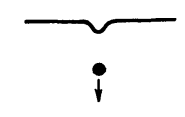

(b)

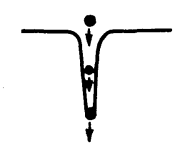

(d)
Fig. 4. Penetration mechanism of solid particles at the liquid surface.

cles fed in unit time and the density of solid particles, and is inversely proportional to the density of liquid.

$$
\mathcal{N}_{j}=\mathcal{N}_{p} U_{o} S_{p}\left(\rho_{s} / \rho_{l}\right)
$$

where, $\mathcal{N}_{p}$ : the number of particle divided by unit volume of a jet of gas

$S_{p}:$ the projected area of one particle.

Figure 5 shows the sectional view of the cavity which is formed with a jet of gas-solid mixture. The lower line corresponds to the formation of type A cavity, and the top line represents the formation of type B cavity. As can be seen from Fig. 5, the lancing condition corresponding to the different type of cavity $\left(\mathrm{A}, \mathrm{A}^{\prime}, \mathrm{B}, \mathrm{B}^{\prime}\right)$ can be separated clearly with the parameter $\mathcal{N}_{j}$ leaving relatively narrow transition range. The $\mathcal{N}_{j}$ value for the plant operation is estimated as $5000 \sim 6000$ which is corresponding to the formation of type B cavity. A detailed study is required for model 3.

\section{Experimental Model for a Jet of Gas-Solid Mixture}

\section{Main Factors Affecting the Penetration Depth}

For the determination of the penetration depth of particles in liquid, various factors which are classified into three groups as mentioned below, are considered in this work.

Lance: diameter $\left(d_{o}\right)$, height $\left(H_{o}\right)$ cone-angle of solid jet

Particle: density $\left(\rho_{s}\right)$, diameter $\left(d_{p}\right)$, injection velocity $\left(U_{o}, U_{s}\right)$, feed rate $\left(W_{s}\right)$

Liquid: density $\left(\rho_{l}\right)$, viscosity $\left(\mu_{l}\right)$

These factors are summarized in Fig. 6 and the properties of materials and liquid used are listed in Table 2.

\section{Particle Velocity and Cone-angle of a Jet of Gas-Solid Mixture}

In general, it is easy to measure the velocity of one isolated particle. But it is very difficult to measure the velocity of one particular particle in a congregated mass. For example the direct method by electronic flash or electromagnetic power and the indirect method by pressure drop are proposed but these are not well established yet. In this experiment using particles of various sizes, the average velocity of par-

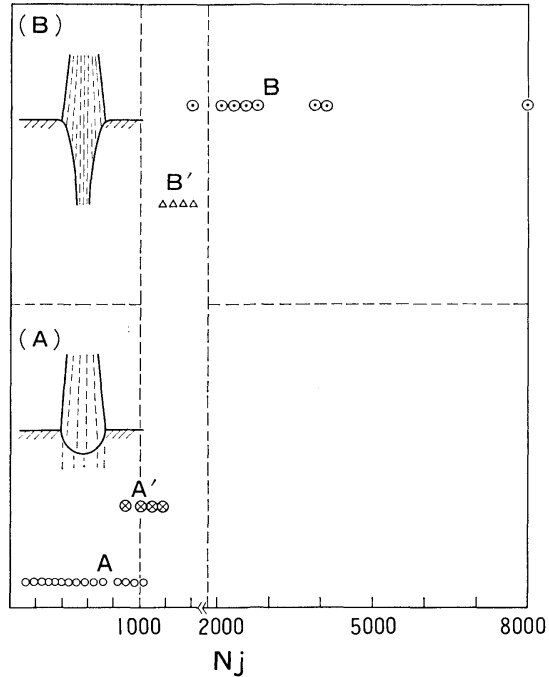

Fig. 5. Sectional view of the cavity which is formed with a jet of gas-solid mixture at various impinging conditions.

$\left(\rho_{\mathrm{g}}, \mathrm{V}\right)$ Gas + solid (dp, Ws,

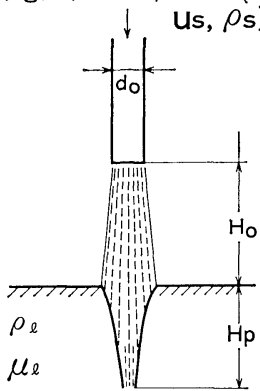

Fig. 6. Various factors on impinging jet.

Table 2. Physical properties of solid particles and liquid.

\begin{tabular}{l|ccc}
\hline Solid particles & $\rho_{s}\left(\mathrm{~g} / \mathrm{cm}^{3}\right)$ & \multicolumn{2}{c}{ dia. $(\mathrm{mm})$} \\
\hline Glass & 2.5 & \multicolumn{2}{|c}{$3.0 \sim 0.05$} \\
Polyethylene & 0.96 & \multicolumn{2}{c}{3.0} \\
Polyacetal & 1.42 & \multicolumn{2}{c}{3.0} \\
\hline \hline Liquid & $\rho_{l}$ & $\begin{array}{c}\mu_{l} \\
\text { (c.p.) }\end{array}$ & $\begin{array}{c}\sigma \\
(\mathrm{dyn} / \mathrm{cm})\end{array}$ \\
\hline Silicon oil & $0.95 \sim 0.98$ & $30 \sim 3000$ & 21 \\
Water & 1.0 & 1.0 & 71 \\
$\mathrm{CCl}_{4}$ & 1.59 & 0.94 & 24 \\
$\mathrm{C}_{2} \mathrm{H}_{2} \mathrm{Br}_{4}$ & 2.96 & 9.6 & 54
\end{tabular}

ticles in a congregated mass was measured by taking photographs under electro flash with $1 / 10000 \mathrm{sec}$ exposure. The results obtained are shown in Fig. 7. It was found that the velocity of particles was equal to the velocity of gas when the size of particles is small.

Next, particle-air jet cone-angle in air $\theta$ was obtained from the photographs of jet, from the outer particle trajectories. The value of $\theta$ was $4.6 \mathrm{deg}$.

3. Particle Distribution in a Cross-section of Jet

The penetration depth is dependent on the particle 


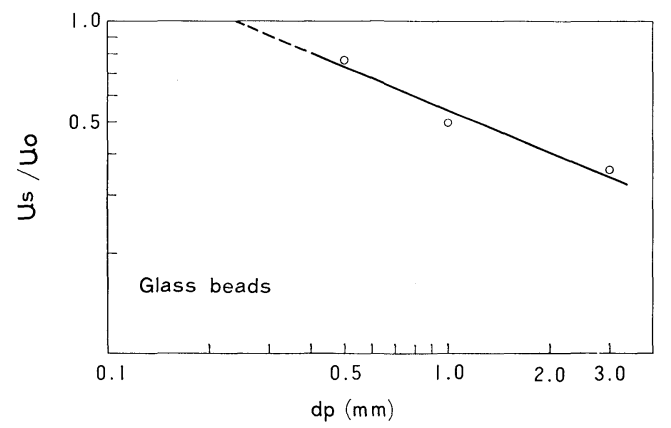

Fig. 7. $U_{s} / U_{o} v s . d_{p}$.

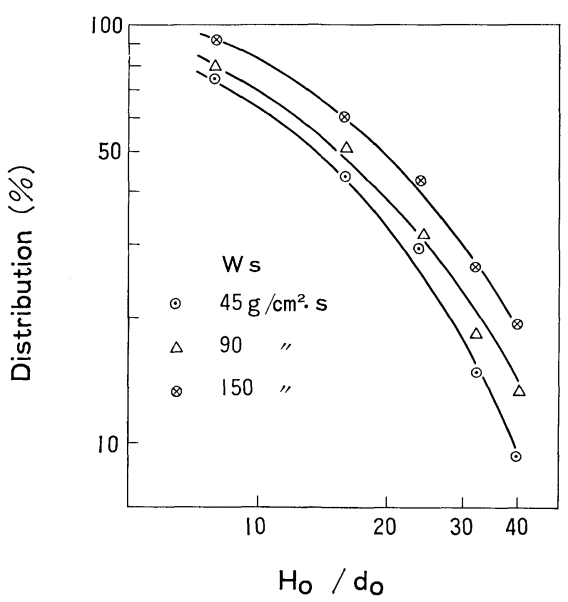

Fig. 8. Distribution vs. $H_{o} / d_{o}$.

distribution in a cross-section of jet. The particle distribution at a cross-section was obtained from the weight of particles captured in a concentric circletype trap. In order to examine the contribution to the penetration depth, it is very important to know the particle distribution at the center of jet.

As a typical example, the particle distribution within $20 \mathrm{~mm}$ circle at the surface of bath is shown in Fig. 8. It depends on particle diameter, gas velocity, feeding rate and height of lance. Particles tend to concentrate at the center of jet, when the particle size is small, gas velocity is low and feeding rate is large. Same tendency was found at a larger lance height. These results are summarized in Eq. (7), which is given by multivariate regression analysis.

$$
\begin{aligned}
\log (\%)= & 1.091-0.999\left(\log \left(H_{o} / d_{o}\right)\right)^{2} \\
& +1.4623 \log \left(H_{o} / d_{o}\right)-0.0843 \log \left(U_{o} / 100\right) \\
& +0.253 \log \left(W_{s} / S_{o}\right) \quad \ldots \ldots \ldots \ldots \ldots \ldots \ldots \ldots \ldots \ldots \ldots \ldots \ldots \ldots \ldots \ldots \ldots \ldots \ldots \ldots \ldots
\end{aligned}
$$

where, $S_{o}$ : the cross-sectional area of lance

$W_{s}$ : the feeding rate of solid particles.

\section{Measurement of Penetration Depth of Particles in Liquid}

The set of variables related to the penetration depth was summarized in Section III. 1. Effects of these variables are shown in Figs. 9 to 13 .

\section{Effects of Particle Velocity, Size and Feeding Rate}

The particle velocity was varied from 10 to $160 \mathrm{~m} /$ sec. The increase in particle velocity caused an increase in penetration depth (Fig. 9). Then the mag-

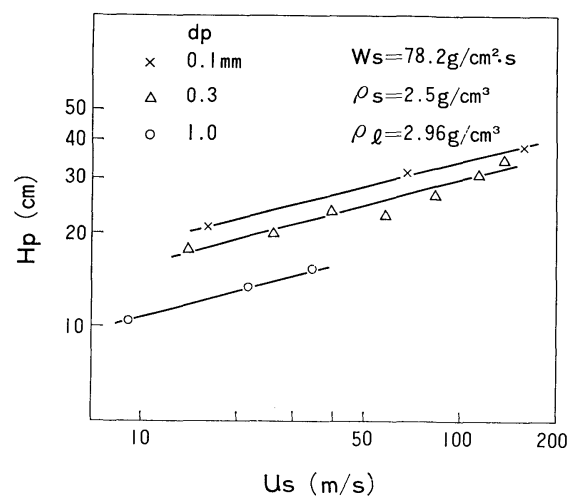

Fig. 9. $H_{p}$ as a function of $U_{s}$.

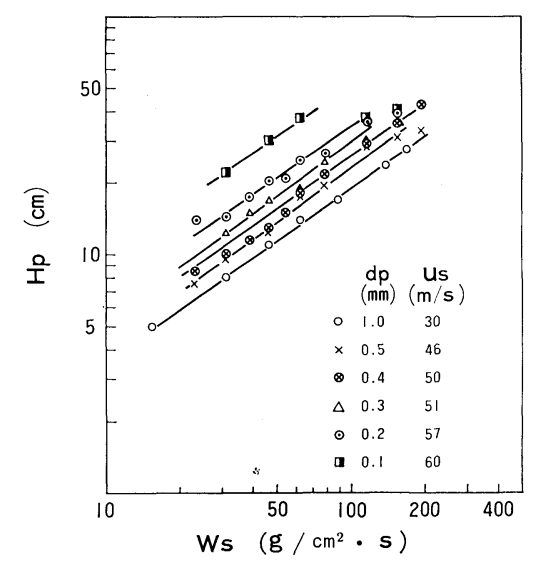

Fig. 10. $H_{p}$ as a function of $W_{s}$.

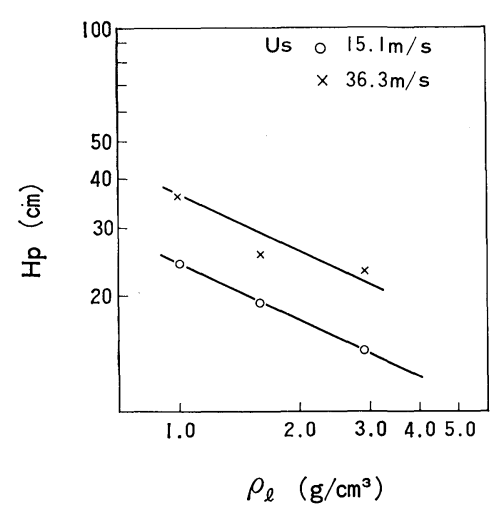

Fig. 11. $H_{p}$ as a function of $\rho_{l}$.

nitude of the increase was the same as in each particle size. The penetration depth became larger at smaller particle size and larger feeding rate. (Fig. 10) From these results, it was found that the increase in number of particles caused an increase in penetration depth, e.g., small particles penetrated more deeply than large particles at the same feeding rate.

\section{Effects of Liquid Density}

The effect of liquid density was tested in the polyethylene-water, carbon tetrachloride, carbon tetrabromide systems. Figure 11 shows that the penetration depth decreased as the liquid density increased.

\section{Effects of Liquid Viscosity}

The increase in liquid viscosity gave a smaller penetration depth. (Fig. 12) 


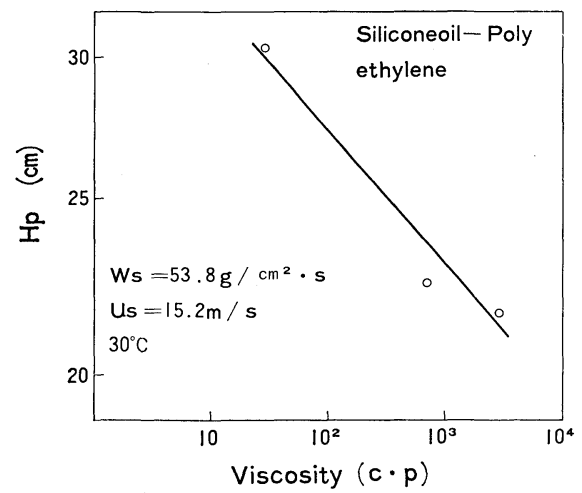

Fig. 12. Effect of viscosity on $H_{p}$.

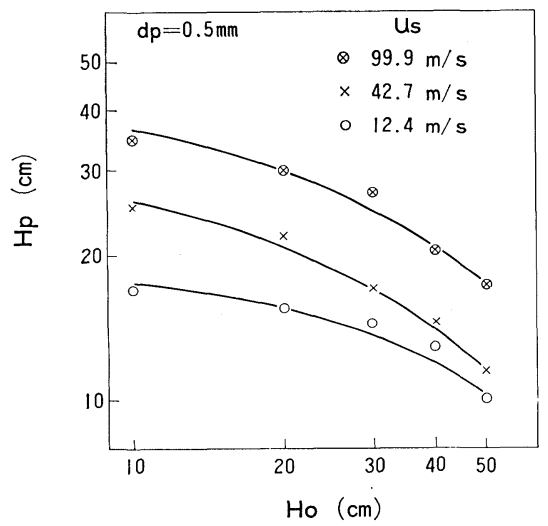

Fig. 13. $H_{p}$ as a function of $H_{o}$.

\section{Effects of Lance Height}

In case of a jet of gas, the increase in lance height caused to decrease the gas velocity and give a smaller cavity depth. But in case of a jet of gas-solid mixture, the velocity of particles at the end of lance was almost equal to the velocity at the liquid surface in the experimental condition adopted.

Therefore the smaller penetration depth of a jet of gas-solid mixture could not be explained by the increase in lance height.

On the other hand, the number of particles at the center of jet of gas-solid mixture, as mentioned in Eq. (7), decreased with increasing distance from the outlet of lance. The decrease in number of particles caused a decrease in penetration depth of particles. From these results, it was found that the increase in lance height gave a smaller penetration depth. (Fig. 13)

\section{Summary}

From the results shown above, Eq. (8) was derived by multivariate regression analysis, which explains the penetration depth of particles.

$$
\begin{aligned}
H_{p}= & 0.136 d_{p}^{1.266} U_{s}^{0.135} \rho_{l}^{-0.609} \rho_{s}^{0.12} \mu_{l}^{-0.024} \mathcal{N}_{p}^{0.494} \\
& \times U_{c}^{0.182}\left(d_{o}+2 H_{o} \tan \theta\right)^{0.475} \quad\left(\rho_{s}<\rho_{l}\right)
\end{aligned}
$$

where, $\mathcal{N}_{p}:$ the feeding rate of particles at the center of jet.

$$
\mathcal{N}_{p}=W_{s} / \frac{\pi}{6} d_{p}^{3} \rho_{s} S_{o} \quad\left(H_{o} / d_{o}<3.8\right)
$$

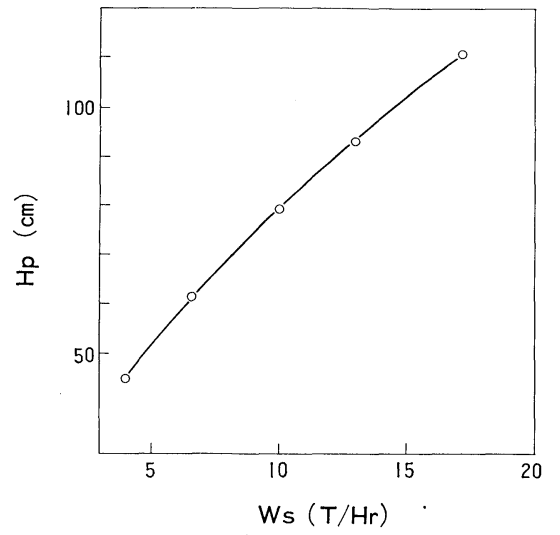

Fig. 14. Penetration depth $\left(H_{p}\right)$ as a function of feeding rate of ore $\left(W_{s}\right)$.

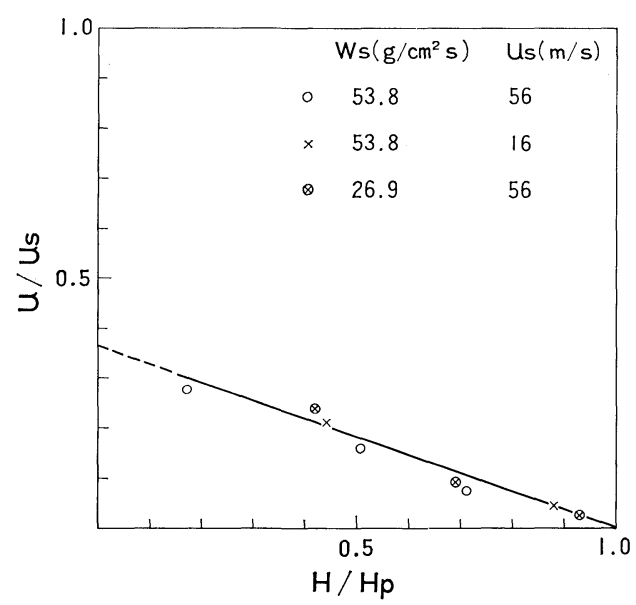

Fig. 15. Solid velocity profile with distance from the liquid surface.

$$
\mathcal{N}_{p}=W_{s} / \frac{\pi}{6} d_{p}^{3} \rho_{s} S_{o} \cdot 10^{(A-2)} \quad\left(H_{o} / d_{o} \geqq 3.8\right)
$$

where, $A: \quad \log (\%)$ as shown by Eq. (7).

Using Eq. (8), the penetration depth of mixed-concentrates was calculated under the operating condition of continuous smelting furnace. The results obtained are shown in Fig. 14.

\section{Behavior of Particles in Liquid}

In case $\mathrm{B}$, a lot of bubbles with impinging particles are produced on the liquid surface. These bubbles make the emulsion phase with gas and liquid around particles, and particles penetrate in gas-liquid mixture, the density of which is lower than that of the liquid. In order to calculate the penetration depth theoretically, the density of gas-liquid mixture must be estimated exactly. On the other hand, the density of gas-liquid mixture varies with the penetration depth in liquid, because the number of bubbles in liquid decreases with increasing penetration depth. It is very difficult to predict the number of bubbles taking with impinging particles.

But it may be possible to predict them by studying the behavior of particles in liquid and the bulk density of gas-liquid mixture around particles is considered to be closely related to the energy consumption 
of particles, which increases with increasing penetration depth in liquid. In the current experiment, the power of collision of particles in liquid was measured as a function of the penetration depth with a stressstrain gage. The results obrained are shown in Fig. 15.

Figure 15 shows that a lot of energy is consumed at the surface of liquid during collision. The energy of particles consumed at the surface of liquid was about $87 \%$ of the initial impinging energy. Furthermore the ratio of particle velocity to the initial one decreased linearly with increasing ratio of penetration depth to the final penetration depth. This fact suggests that the theoretical analysis should be made on the particle behavior in gas-liquid mixture.

\section{Examination of Results Obtained by Cold Model Simulation Using High-temperature Experimental Technique}

In the cold model simulation, there are neither smelting nor reaction. It is important to grasp the applicability of the cold model simulation results to the actual operating condition. So laboratory scale high temperature model tests were made.

\section{Experimental Procedure}

The experimental conditions adopted in a high temperature injection are as follows:

Vessel: carbon crucible, $160 \mathrm{~mm}$ long, $400 \mathrm{~mm}$ dia.

Lance: stainless steel pipe, $5.0 \mathrm{~mm}$ or $3.0 \mathrm{~mm}$ inner dia.

Feeding rate: $4 \mathrm{~g} / \mathrm{s} \sim 15 \mathrm{~g} / \mathrm{s}$

Gas velocity: $140 \mathrm{~m} / \mathrm{s}\left(20^{\circ} \mathrm{C}\right)$

Feed material: mixture of copper concentrate, silica and lime

Liquid bath: molten matte

Then the concentration of calcium was used as the parameter to know the penetration depth into matte, because the matte used did not contain calcium.

The sampling of matte at a predetermined period was done with a quartz sampling tube. The sample was quenched and analyzed.

\section{Results}

The penetration depth measured by monitoring the concentration of calcium in molten matte was compared with the penetration depth calculated by Eq. (8) which is shown in Table 3. Equation (8) was much effective for the prediction of the penetration depth of a injection energy in a commercial op-

Table 3. Comparison between the depth of cavity measured by hot model and calculated depth of cavity.

\begin{tabular}{c|cc}
\hline Exp. No. & $\begin{array}{c}\text { Measured depth } \\
(\mathrm{cm})\end{array}$ & $\begin{array}{c}\text { Calculated depth } \\
(\mathrm{cm})\end{array}$ \\
\hline 1 & $16.0 \sim 18.0$ & 17.0 \\
2 & $20.0 \sim 24.0$ & 21.9 \\
3 & $13.0 \sim 16.0$ & 13.5 \\
4 & $13.0 \sim 16.0$ & 16.3 \\
5 & $16.0 \sim 19.0$ & 15.6 \\
\hline
\end{tabular}

eration.

\section{Conclusion}

The penetration behavior of a jet of gas-solid mixture, which caused the formation of cavity (type A) or not (type $\mathrm{B}$ ), was characterized by impinging conditions. A new parameter, $\mathcal{N}_{j}$, was introduced to determine the type, and the depth of cavity was estimated by Eq. (5) in case of type A. Further, Eq. (8) was derived experimentally to determine the penetration depth of a jet of gas-solid mixture into liquid in case of type B, but the effect of surface tension was not considered.

The reliability of the equation at the actual operating condition was confirmed by making hot model tests. The result obtained is useful to estimate the effect of the injection energy on the bottom wear of the continuous smelting furnace.

\section{Nomenclature}

$C_{d}:$ drag coefficient

$d_{o}:$ diameter of lance $(\mathrm{cm})$

$d_{p}$ : diameter of particle $(\mathrm{cm})$

$g$ : accerelation of gravity $\left(980 \mathrm{~cm} / \mathrm{s}^{2}\right)$

$H:$ depth in liquid $(\mathrm{cm})$

$H_{c}:$ depth of cavity $(\mathrm{cm})$

$H_{o}$ : lance height $(\mathrm{cm})$

$H_{p}$ : penetration depth of particles

$K_{j(g)}, K_{j(s)}$ : jet constant of gas or solid jet

$\mathcal{N}_{p}$ : number of particles/unit gas volume of gas jet $\left(l / \mathrm{cm}^{3}\right)$

$S_{o}: \quad$ sectional area of nozzle $\left(\mathrm{cm}^{2}\right)$

$S_{p}:$ projected area of one particle $\left(\mathrm{cm}^{2}\right)$

$U:$ solid particle velocity in liquid

$U_{c}:$ gas axial velocity of jet $(\mathrm{cm} / \mathrm{s})$

$U_{o}$ : gas flow rate at the outlet of lance $(\mathrm{cm} / \mathrm{s}, \mathrm{m} / \mathrm{s})$

$U_{s}:$ particle velocity at the outlet of lance $(\mathrm{cm} / \mathrm{s}$, $\mathrm{m} / \mathrm{s}$ )

$V:$ volume of gas injected $\left(\mathrm{cm}^{3} / \mathrm{s}\right)$

$W_{s}$ : feeding rate of solid particles $\left(\mathrm{g} / \mathrm{cm}^{2} \mathrm{~s}\right)$

$\alpha$ : contribution of particles to the formation of cavity

$\theta: \quad$ cone-angle of solid jet

$\mu_{l}: \quad$ viscosity of liquid (c.p.)

$\rho_{s}:$ density of solid particles $\left(\mathrm{g} / \mathrm{cm}^{3}\right)$

$\rho_{g}:$ density of gas $\left(\mathrm{g} / \mathrm{cm}^{3}\right)$

$\rho_{l}:$ density of liquid $\left(\mathrm{g} / \mathrm{cm}^{3}\right)$

$\rho_{g}^{*}$ : apparent average density of gas-solid mixture $\left(\mathrm{g} / \mathrm{cm}^{3}\right)$

$\rho_{s g}: \quad$ weight of particles/unit gas volume $\left(\mathrm{g} / \mathrm{cm}^{3}\right)$

$\sigma:$ surface tension $(\mathrm{dyn} / \mathrm{cm})$

\section{Acknowledgements}

The author would like to express his appreciation to Dr. T. Suzuki, Managing Director of Mitsubishi Metal Corp. and Mr. T. Shibazaki, Manager, Department of Process Technology, Mitsubishi Metal Corp. for their advices and permission to publish this paper.

\section{REFERENGES}

1) T. Nagano and T. Suzuki: Extractive Metallurgy of Cop- 
per, I, The Metallurgical Society of AIME, New York, (1976), 439.

2) M. Goto and T. Echigoya: J. Metals, (1980), No. 11, 6.

3) D. H. Wakelin: Ph.D. Thesis, Imperial College, University of London, (1966).
4) K. Segawa, S. Maehara, M. Shimada and M. Ishibashi: Iron Steel, 44 (1958), 1056.

5) Takeda: Ph. D. Thesis, (1961).

6) T. A. Engh, K. Larsen and K. Venas: Ironmaking and Steelmaking, 6 (1979), 268. 